\title{
A new species of Leschenaultia Robineau-Desvoidy (Diptera, Tachinidae) from Venezuela and new geographical records
}

\author{
Ronaldo Toma ${ }^{1}$ \\ ${ }^{1}$ Universidad de Carabobo, Facultad de Ciencias y Tecnología, Departamento de Biología, Bárbula, antiguo Decanato de Ciencias de la Salud, \\ Valencia, Carabobo, C.P. 2005. rtkuna1@gmail.com
}

\begin{abstract}
A new species of Leschenaultia Robineau-Desvoidy (Diptera, Tachinidae) from Venezuela and new geographical records. Leschenaultia barbarae sp. nov. is described from Cojedes state, Venezuela. This species is similar to Leschenaultia bicolor (Macquart, 1846) but can be distinguished from this species by the combination of the following characters: anterior tarsal claws longer than second tarsomere of the same leg, and cerci, in lateral view, finer and no so strongly curved back as in L. bicolor (Macquart).
\end{abstract}

KEYWORDS. Geographic record; Neotropical; taxonomy.

RESUMO. Uma espécie nova de Leschenaultia Robineau-Desvoidy (Diptera, Tachinidae) para Venezuela e novos registros geográficos. Leschenaultia barbarae sp. nov. é descrita de um material do Estado de Cojedes, Venezuela. Esta especie é semelhante a L. bicolor (Macquart), mas pode ser diferenciada desta através de uma combinaçao de caracteres: garra tarsal anterior mais longa que o segundo tarsômero; cercos, em vista lateral, mais delgado e não tão fortemente curvado para trás como em L. bicolor (Maquart).

PALAVRAS CHAVES. Registro geográfico; Neotropical; taxonomia.

Leschenaultia was described by Robineau-Desvoidy (1830) and was placed within the Harrisini by Townsend (1936) but recently its systematic placement has changed within the Goniini (O‘Hara \& Wood, 2004). The geographic distribution is restricted to the New World (Guimarães, 1971; O'Hara \& Wood, 2004). According to Toma \& Guimarães (2002) this genus presents 32 species with 19 species recorded to Neotropical Region and three species to Venezuela: L. braueri Toma \& Guimarães, 2002, L. cortesi Toma \& Guimarães, 2002 and L. leucophrys (Wiedemann, 1830). In the present work a new species from Venezuela is described and new geographic records are done for the genus. The material studied here belongs to Museo del Instituto de Zoología Agrícola Francisco Fernández Yépez (MIZA) and the morphological terminology follows Mcalpine (1981) and the term pro-frons from Crosskey (1984).

\section{Leschenaultia barbarae Toma sp. $\mathbf{n}$.}

(Figs. 1,2)

Type material. Male holotype (MIZA), Venezuela, Cojedes states ("carretera Manrique a Sierra"); 28 january 1983; leg. F. Fernandez, J. Clavijo and J. De marmels.

Etymology. The name is given in homage to my daughter Barbara Hitomi.

Diagnosis. Parafacials with hairs extending just below the upper third. One pair of apical bristles reduced. Sintergite $1+2$ and tergite 3 without discal bristles and median marginal bristles. Tergite 4 with a row of median marginal bristles. Anterior tarsal claws longer than the second tarsomere of the same leg.
Length. $10 \mathrm{~mm}$

Description. Head black with grey pruinosity, stronger on the parafacials, face and gena; frons brown; vertex a little more than 0.25 the length of the head width; pro-frons smoothly projecting, a little higher than middle of eye-height; frontoorbital plate almost twice the width of frontal vitta; pro-frons almost two and a half times as wide as the frontal vitta; parafacial a little less than twice as wide as flagellomere just bellow its base and a little less than double width of first flagellomere at subapical portion; antenna black, first flagellomere about twice the length of the pedicel; palpus orangish; outer vertical seta short; a row of about 11 frontal bristles extending to the upper third of the parafacial; parafacial with hairs extending just below the upper third; facial ridge with bristles varying from 0.20 to 0.40 the length of the vibrissa, extending close to 0.50 of the distance from the vibrissa to the antennal base, bordered by smaller setae; gena a little less than one third of eye-height.

Thorax black; postalar callus and scutellum brown; pruinosity grey mainly on the scutum, brown on the postalar callus and scutellum. Scutellar bristles: one pair of basal; one pair of lateral; one pair of sub-apical; one pair of apical bristles reduced; a small group of bristles among the discal bristles; legs black; anterior tarsal claws longer than the second tarsome of the same leg. Wing: calypters with brown-yellowish pruinosity.

Abdomen brown, darkened centro-longitudinally with brown pruinosity. Syntergite $1+2$ and Tergite 3 without discal bristles and median marginal bristles. Tergite 4 with a row of median marginal bristles and with one bristle that could be 

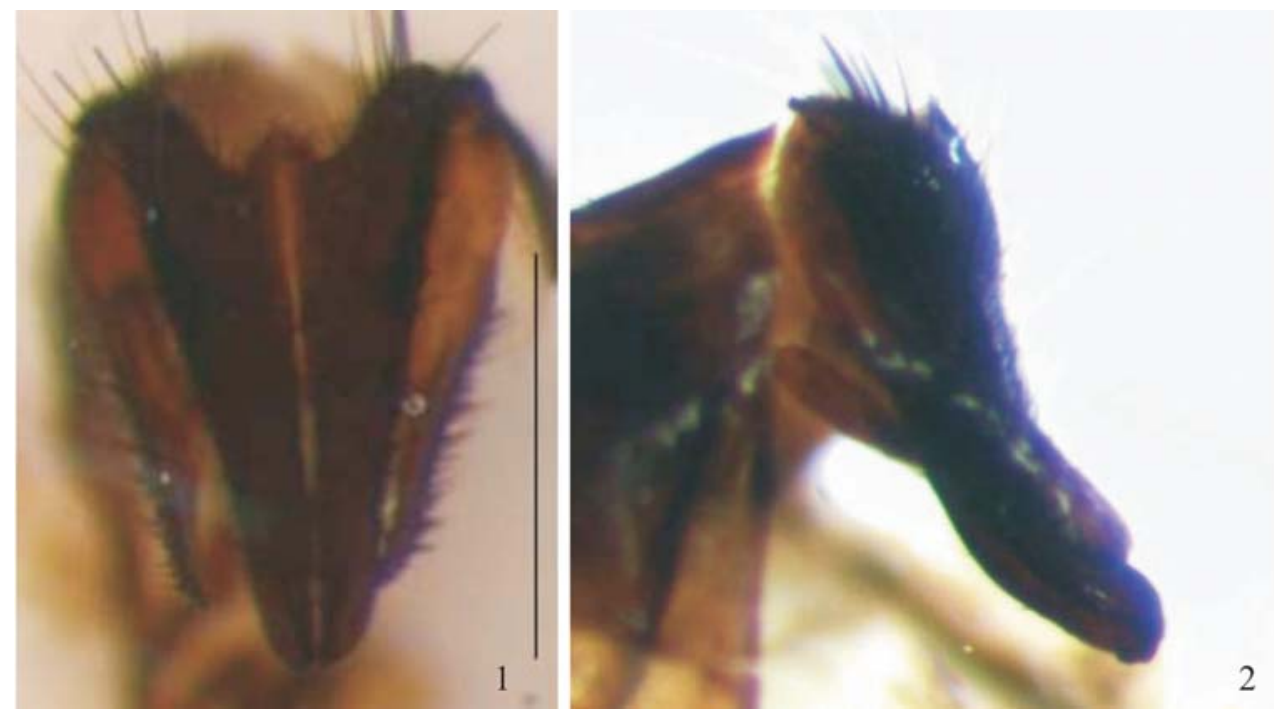

Figs 1-2. Leschenaultia barbarae Toma, sp. nov.: 1, male terminalia, posterior view; 2, same, lateral view. (Scale bar: $0.5 \mathrm{~mm}$ ).

part of a small group of short discal bristles.

Cerci and surstyli (Figs. 1,2), in lateral view, cerci with the posterior portion strongly curved backward but the curvature is less strong than in the L. bicolor. Surstyli about 0.80 the length of cerci.

Female: unknown.

Commentary. This species is described based on male holotype and is similar to Leschenaultia bicolor, and in the key to the Neotropical species of Toma \& Guimarães (2002) runs to L. bicolor, but differs from this species by having anterior tarsal claws longer than the second tarsomere of the same leg, by the cerci, in lateral view, finer and not so strongly curved back, and by the tergite 4 with one bristle that could be part of a small group of short discal bristles.

\section{New records on geographic distribution to Venezuela}

\section{Leschenaultia bigoti Toma \& Guimarães, 2002}

Examined material: Venezuela (MIZA): 1 male; Aragua state, Rancho Grande, $1100 \mathrm{~m}$; leg. L. D. Otero. 1 male; Falcon state, Curimagua, 940 m; 27 november 1971; leg. R. Casares, J. B. Terran and C. Padrón.

Commentary: This species was previously recorded to Mexico, Honduras, Costa Rica, Brazil, Ecuador and Peru.

\section{Leschenaultia brooksi Toma \& Guimarães, 2002}

Examined material: Venezuela (MIZA): 3 males; Lara state, Sabana Alta, 600 m; 13 january 1976; leg. J. Salcedo. 4 males and 6 females; Anzoategui, San Diego de Cabrutica; 19 October 2000; leg. A. Montagne and Z. Tiape. 1 male; Tachira state ("Quebrada la Uraca"), $300 \mathrm{~m}$; 17 22 Jun 1998, J. De Marmels and Chacon.
Commentary: This species was previously recorded to Mexico, Panama, Peru and Brazil.

\section{Leschenaultia currani Toma \& Guimarães, 2002}

Examined material: Venezuela (MIZA): 1 male; Caracas, El Valle; 11 february 1960; leg. F. Fernandez.

Commentary: This species was previously recorded to Brazil.

Acknowledge. Thanks to José Clavijo (MIZA) for the loan of material. This study was developed at the Department of Biology, FACYT.

\section{REFERENCES}

Crosskey, R. W. 1984. A annotated keys to the genera of Tachinidae (Diptera) found in tropical and south African. Annls of the Natal Museum 26: 189-337.

Guimarães, J. H. 1971. 104. Family Tachinidae. In: N. Papavero (ed.). A catalog of the Diptera of the Americas South of the United States. São Paulo, Museu de Zoologia, Universidade de São Paulo, $333 \mathrm{p}$.

Mcalpine, J. F. 1981. Morphology and terminology, p. 9-63. In MCALPINE, J.F. et al. (eds). Manual of Neartic Diptera. Ottawa, Agriculture Canada, Research Branch Monograph 27, vol. 1674 p.

O'Hara, J. E. \& D. M. Wood. 2004. Catalogue of the Tachinidae (Diptera) of America north of Mexico. Memoirs on Entomology, International 18: $410 \mathrm{p}$.

Robineau-Desvoidy, J. B. 1830. Essai sur les Myodaires. Paris. Mémoire présentés par divers Savans à l'Acaddémie Royale des Sciences des l'Institut de France 2: 1-813.

Toma, R. \& Guimarães, J. H. 2002. Estudo taxonômico de Leschenaultia Robineau-Desvoidy (Diptera, Tachinidae). Revista Brasileira de Entomologia 46: 33-70.

Tonwnsed, C. H. T. 1936. Manual of Myiology (in twelve parts). Oestroid classification and habits (Dexiidae and Exoristidae). Itaquaquecetuba, C. Townsend \& Filhos. Pt.1V, 303p. 